\title{
Covalent Bonds Creation between Gas and Liquid Phase Change: Compatibility with Covalent and Even-Odd Rules Based on a "Specific Periodic Table for Liquids"
}

\author{
Geoffroy Auvert \\ Grenoble Alpes University, Grenoble, France \\ Email: geoffroy.auvert@grenoble-inp.org
}

How to cite this paper: Auvert, G. (2020) Covalent Bonds Creation between Gas and Liquid Phase Change: Compatibility with Covalent and Even-Odd Rules Based on a "Specific Periodic Table for Liquids". Open Journal of Physical Chemistry, 10, 68-85. https://doi.org/10.4236/ojpc.2020.101004

Received: January 14, 2020

Accepted: February 25, 2020

Published: February 28, 2020

Copyright $\odot 2020$ by author(s) and Scientific Research Publishing Inc. This work is licensed under the Creative Commons Attribution International License (CC BY 4.0).

http://creativecommons.org/licenses/by/4.0/ (c) (i) Open Access

\begin{abstract}
A decrease in temperature will eventually turn a gas into liquid and then into a solid. Each of these phase change shows a higher degree in cohesion of molecules. While it is usually admitted that molecules in solids form additional connections, the cohesion of molecules in liquids is usually explained by changes in kinetics of molecules. Given that the density of a solid is nearly the same than that of a liquid, the present paper assumes a different stand and considers that connections between molecules must be similar in liquids and in solids. The difference between gas, in which molecules are entirely loose, and liquid, is therefore the presence of an additional connection between gaseous molecules. This paper describes how and where these connections are built with the help of a few rules and a "specific periodic table for liquids". The coherence of this approach is reinforced by its capacity to explain phase change of forty well-known molecules containing inorganic and organic elements.
\end{abstract}

\section{Keywords}

Covalent Bond, Even-Odd Rule, Liquid, Gas, Periodic Table, Molecule, Association, Dissociation

\section{Introduction}

Molecules in gases are totally free from one another and they fill the entire volume they are offered. Small variations in pressure or temperature do not modify the structure of gaseous molecules. On the opposite, in the solid state, molecules are predominantly held together through several covalent bonds. Thanks to 
these bonds, the solid is uncompressible and no internal movement is possible. In the intermediate state, liquid, the medium is fluid like in a gas, but incompressible like a solid. However, the reason for this is not clearly explained in scientific publications [1]. The objective of this paper is to propose a model of the liquid state. It will give a detailed chemical understanding of what happens when gases become liquids.

The main idea exposed here, is that a liquid is formed when physical conditions are reached for molecules to build their first covalent bonds. In other words, liquefaction occurs when some atoms of two gaseous molecules connect with a new covalent bond. The liquid is hence composed of molecules held to one another through a unique covalent bond. This structure remains unchanged until physical conditions impose the formation of other covalent bonds, inducing a change into solid state.

After giving a few rules to root our concept, we will explain here that this bond holding liquid molecules together is composed of an electron pair coming from the inside of an atom. It will be shown that liquefaction transformations maintain electrical neutrality of molecules. To finally demonstrate its simplicity and logic, the concept is applied to forty well-known molecules [1].

In the present article:

- compounds are in the form of molecules therefore ions are excluded,

- each atom in a compound is either neutral or with a single, positive or negative, charge [2],

- atoms are represented by their acronyms as in the classical periodic table [3],

- the drawing of a small line between two atoms represents a covalent bond [4] [5],

- to remain conform to notations used in previous papers dealing with the even-odd rule, compounds are noted in capitals: $\mathrm{NH} 3$ is for neutral ammonia, $\mathrm{NH} 4(+)$ for ammonium and $\mathrm{NH} 2(-)$ for amide ions [4] [5].

\section{Tools and Rules}

We expose here a few rules and a specific table for chemistry that will be used in explaining how a covalent bond is created between molecules to form a liquid [6].

\subsection{Even-Odd Rule: Basic Concepts of Atoms in a Compound}

Molecules are composed of atoms linked through bonds. These bonds are covalent bonds composed of electron pairs [7]. In former publications, a rule named even-odd rule has been described and clarifies how many covalent bonds an atom erects [4]. This rule has successfully been applied to small molecules with central neutral atoms [4], then to ions with a central charged atom [5].

Noteworthy for the present article, atoms only erect single bonds with neighboring atoms and never with multiple bonds [8]. This modification (compared to classical theory) has a direct consequence on positions of charged atoms in a 
compound [9]. The procedure also asserts that atoms are neutral or with only a single charge [2].

This rule depends on the number of electrons an atom has in a compound. Briefly recalled, it states that:

- Neutral even atoms have an even number of bonds,

- Neutral odd atoms have an odd number of bonds,

- Atoms with single charge have a reversed parity of the numbers of bonds compared to neutral atoms.

Lastly, this rule is equally applied to compounds having organic and/or inorganic atoms [10].

\subsection{Covalent Bonds Rule}

In a compound, atoms are classically related to each other by some different ways [11]. Although classical theory has introduced many different types of intermolecular forces, the underlying concept in all past articles, as well as in the present one, is that connections between atoms are always covalent. These covalent bonds are:

- composed of one electron pair [12]

- with only a single covalent bond between two connected atoms [8]

- connecting two neutral atoms or one neutral atom to a single charged atom or two different charged atoms [12]

- not allowed to connect atoms having the same positive or negative charge [12].

\subsection{Electronic Structure of an Atom in a Compound}

The electronic structure of an atom in a compound can be described as [7]:

- around a nucleus, three shells are present: inner, inactive and covalent shells,

- the two first shells are composed of electron pairs,

- the third shell contains one electron for each covalent bond an atom possesses. This electron is a part of an electron pair and the other electron belongs to the other connected atom. It also means that electrons in a covalent shell belong to this atom i.e. the number of electrons in its covalent shell is equal to the number of covalent bonds.

In this electronic structure, the total number of electrons of an atom in a compound is always even. This occurs whatever the electrical charge of the compound and whatever the current phase (solid, liquid or gaseous) [12]. Such electronic structures have been tested on well-known crystals [13] [14].

\subsection{Periodic Table for Liquids}

To simplify the understanding of the structures, a specific periodic table was introduced [12]. This table indicates numbers of bonds for an atom and the influence of the charge [10] [12]. The enhanced periodic table has been tested against chemical dissociation of medium sized molecules [15]. Unfortunately, this peri- 
odic table was not applicable in this paper which needs a "specific periodic table for gas to liquids transformations". This different periodic table must be valid for compounds in a liquid form. Such a periodic table is presented in Table 1.

Table 1. First two rows of the Specific periodic table for liquids formations. The classification in columns of the atoms is using numbers of electrons starting from 1 for hydrogen up to 7 for fluorine. The classification of neutral atoms, in rows and in columns is identical to the classical periodic table. Charged atoms are positioned in the two nearest columns of the neutral atoms. White cells are with inorganic atoms and green cells with organic atoms. In column 4, Carbon in yellow color is classified as a semi-organic atom.

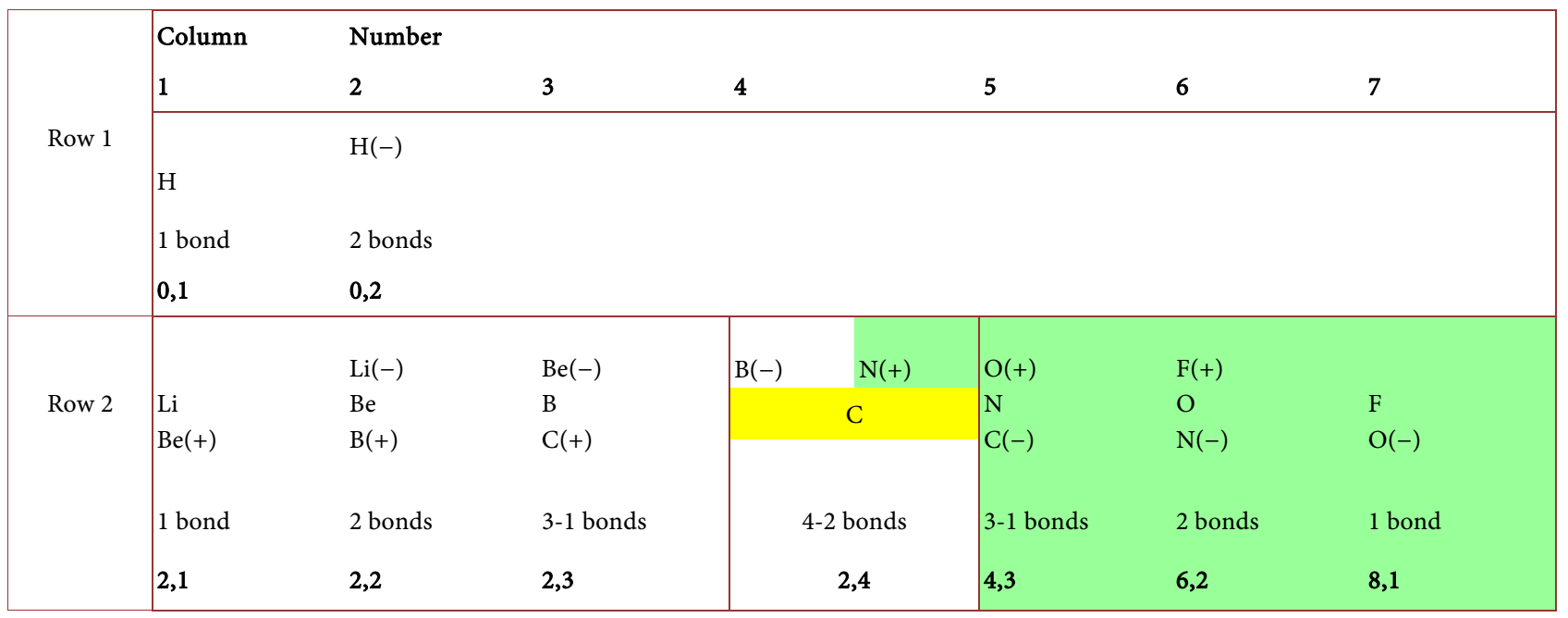

Drawings in this table have the following particularities:

- atom's acronyms are used as in the classical periodic table,

- neutral atoms are classified by columns as in the classical periodic table,

- charged atoms bear only single charges,

- neutral and charged atoms are placed according to their number of electrons,

- when two different atoms: charged or uncharged, have the same number of electrons, they are placed in the same cell.

- atoms are always bonded and are parts of molecules.

This table can be understood as follows:

- The first row has two cells with $\mathrm{H}($ neutral) and $\mathrm{H}(-)$ with respectively one and two bonds.

- The second row has seven cells starting with Li(neutral) up to neutral fluorine.

- In the same row, the highest number of bonds increases from one to four and then decreases down to one.

- In column 3 to 5 , two bonding configurations are possible: Neutral nitrogen in column 5 , can be found with either 3 or 1 bonds.

- The numbers placed at the lowest positions in each cell gives the number of electrons in the inner shell and the number of electrons in the other shells: 2 , 1 for Li(neutral). Adding these two numbers of a cell to each other gives the total number of electrons of the atoms placed in this cell.

- In row 2, the three first cells in white color are composed of inorganic atoms. 
i.e. the number of electrons in the inner shell is constant,

- The three last cells in green color are composed of organic atoms i.e. the number of electrons in the inner shell is increased by step of two from left to right.

- In the middle, column 4, the cell is occupied with several atoms: an inorganic charged atom $\mathrm{B}(-)$, an organic charged atom $\mathrm{N}(+)$ and a semi-organic atom in yellow color $\mathrm{C}$ (neutral).

This "specific periodic table for gas to liquids transformations" will be very useful to follow changes of numbers of bonds and charges positions during chemical transformations.

\section{What Happens during the Gas to Liquid Phase Transition?}

\subsection{Molecular Connections from Gas to Liquid}

Some molecules can be represented with atoms A and B, with groups of atoms R1 R2 R3, and with lines for covalent bonds as follow:<smiles>[R][R][R][R]</smiles><smiles>[R][R][R][H]</smiles>

In this drawing, single atoms $\mathrm{A}$ or $\mathrm{B}$ are connected by covalent bonds to groups R. These last groups are composed of atoms structured by covalent bonds between neighboring atoms. They can have any number of atoms.

A liquid is formed when several gaseous molecules establish a new connection with a covalent bond. Starting with the previously described molecules, these connected molecules can be drawn as follow:

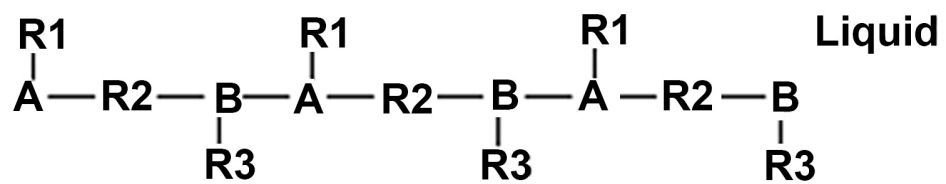

Atoms B and A are now connected with a covalent bond. It can be said that an association has occurred. This association may form very large molecules. These large molecules can move slowly in liquids, but they cannot be compressed. Consequently, a liquid is made of many large molecules, like these ones, as in organic oils [16].

\subsection{Electrons' Positions in Molecules}

Chemistry of a molecular association depends on the parity of atoms A and B which interact [2]. Three options are possible: even-even, odd-odd and even-odd.

In the three-following drawing: electrons form pairs which are represented by a line ended by two points. When composing a bond, each point represents an 
electron which belongs to only one atom, but they are still composing a covalent bond.

In the following drawings, symbol $\mathrm{n}$ is an even number and symbol $\mathrm{m}$ has the parity of its nucleus.

\subsubsection{Two Even Atoms to be Associated}

In gas and liquid phases, electrons positions between two even atoms can be drawn as:

\begin{tabular}{|c|c|c|c|c|}
\hline & Even atom & Even atom & Grou & quid \\
\hline Nucleus name & B & A & $\mathrm{B}(+)$ & $A(-)$ \\
\hline Inner shell & $\mathrm{n} 2$ & $\mathrm{n} 1$ & $\mathrm{n} 2$ & $\mathrm{n} 1$ \\
\hline Inactive shell & $m 2-2$ & $\mathrm{~m} 1-2$ & $m 2-4$ & $\mathrm{~m} 1-2$ \\
\hline Covalent shell & 110 & 0 & 1 & $\bullet 11$ \\
\hline
\end{tabular}

In this drawing, electron pairs are shown below the nucleus in three shells: an inner shell with $\mathrm{n}$ electrons, an inactive shell with $\mathrm{m}$ electrons and a covalent shell.

In the inner shell, the number of electrons is not changed by the gas to liquid transformation. This is different for electron pairs of the inactive shell [10].

Covalent shells in the two first atoms have two electron pairs forming two covalent bonds: with R1 and R2 for atom A; with R2 and R3 for atom B.

To build a group with one covalent bond, an electron pair of the inactive shell of atom B must move: number (m2-2) becomes (m2-4) in $B(+)$. This pair appears in two covalent shells: one electron in $\mathrm{A}$ and the other electron stays in $\mathrm{B}$ but in its covalent shell. Atom $\mathrm{B}$ has lost one electron and has become $\mathrm{B}(+)$. Atom $\mathrm{A}$ has received one electron from $\mathrm{B}$ and has become $\mathrm{A}(-)$. The total number of electrons is unchanged, as expected.

\subsubsection{Odd Atoms}

In gas and liquid, electron positions between odd atoms can be drawn as:

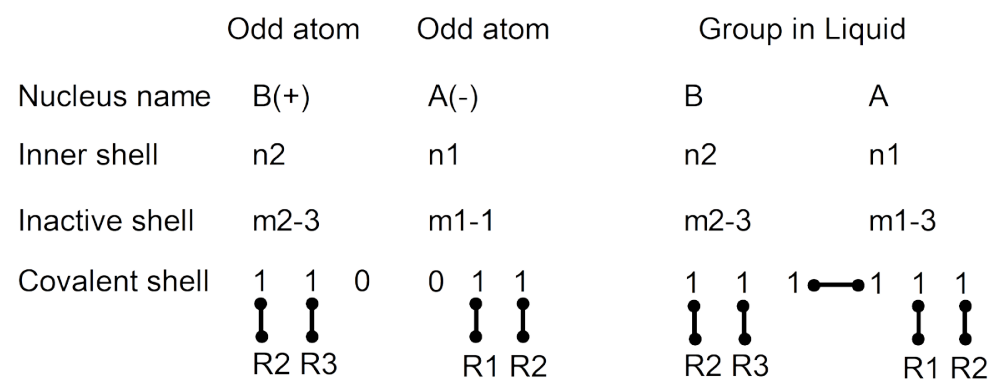

In this drawing, left atom $\mathrm{B}$ has one missing electron and atom $\mathrm{A}$ has one added. This is necessary to keep electrons pairs everywhere around each nucleus 
of the compounds.

In this drawing, as in the previous one, the number of electrons in the inner shell is not changed by the transformation. In the inactive shells, $\mathrm{m}$ is odd and to obtain even numbers, they must be changed as: (m2-3) and (m1-1) into (m2-3) and (m1-3).

When $\mathrm{A}$ and $\mathrm{B}$ are gathered (right side in this drawing), both atoms are uncharged and have a new covalent bond. One electron of atom A has moved into the covalent shell of atom B. The other electron has moved into the covalent shell of atom A. This electron pair has not been destroyed and their covalence is still valid.

\subsubsection{One Odd and One Even Atoms}

Electrons positions between an odd atom and an even atom in gas to liquid transformation can be drawn as:

\begin{tabular}{|c|c|c|c|c|}
\hline \multirow[b]{2}{*}{ Nucleus name } & \multirow{2}{*}{$\begin{array}{l}\text { Odd atom } \\
\text { B(-) }\end{array}$} & \multirow{2}{*}{$\begin{array}{l}\text { Even atom } \\
\text { A }\end{array}$} & \multicolumn{2}{|c|}{ Group in Liquid } \\
\hline & & & B & $A(-)$ \\
\hline Inner shell & $\mathrm{n} 2$ & $\mathrm{n} 1$ & $\mathrm{n} 2$ & $\mathrm{n} 1$ \\
\hline Inactive shell & $\mathrm{m} 2-1$ & $\mathrm{~m} 1-2$ & $\mathrm{~m} 2-3$ & $\mathrm{~m} 1-2$ \\
\hline Covalent shell & $\prod_{\mathrm{R} 2 \mathrm{R} 3}^{1} \mathfrak{l}^{1} 0$ & $\begin{array}{lll}0 & 1 & 1 \\
R & \text { ? } & R 2\end{array}$ & $\begin{array}{ll}1 & 1 \\
\text { ? } 2 & \text { R3 }\end{array}$ & R1 \\
\hline
\end{tabular}

In this drawing, left atom $\mathrm{B}$ has one added electron i.e. $\mathrm{B}(-)$. Atoms $\mathrm{A}$ and $\mathrm{B}(-)$ have an even number of electrons. In the inactive shell, as $\mathrm{m} 2$ is odd, numbers $\mathrm{m} 2-1$ and $\mathrm{m} 2-3$ are even numbers.

When $B$ and $A$ are gathered, one electron pair in $B$ has moved to form a bond between $\mathrm{A}$ and $\mathrm{B}$. Atom $\mathrm{A}$ becomes $\mathrm{A}(-)$ and atom $\mathrm{B}(-)$ becomes $\mathrm{B}$ (neutral). The inactive shell of atom $B,(\mathrm{~m} 2-1)$ becomes (m2-3): it has lost one pair. This pair appears in the covalent shells. Consequently, when atoms $\mathrm{A}$ and $\mathrm{B}$ are gathered, they have 3 bonds.

In this drawing, all electrons form pairs and only one electron pair has moved to form a liquid. It seems that (see nucleus in the first row) a single electron has moved from left to right. The change of $\mathrm{B}(-)$ with $\mathrm{A}$ (neutral) into $\mathrm{B}$ (neutral) with $\mathrm{A}(-)$ is not obtained by a change of a single electron.

Consequently, from all these drawings, in gas to liquids transformations, only two atoms are concerned and the number of bonds for these coupled atoms is always increased by one.

\section{Application: Gas to Liquid Transformations}

In this chapter, gaseous molecules and liquid structures are drawn. Structures of molecules are well-known [1] [6] [17], but their liquids structures are not. Table 2 
Table 2. Molecules in gaseous and liquid phase with their temperature in liquid phase. Column 1 gives the couple of atoms going to be associated for liquid formations. Column 2 gives the name of compounds allowing the formations of these bonds. Column 3 gives the number of bonds of the atoms before and after the liquid transformation and the temperature range of the liquid phase. Column 4 shows the drawings of the gas and the liquids using the molecule of column 2.

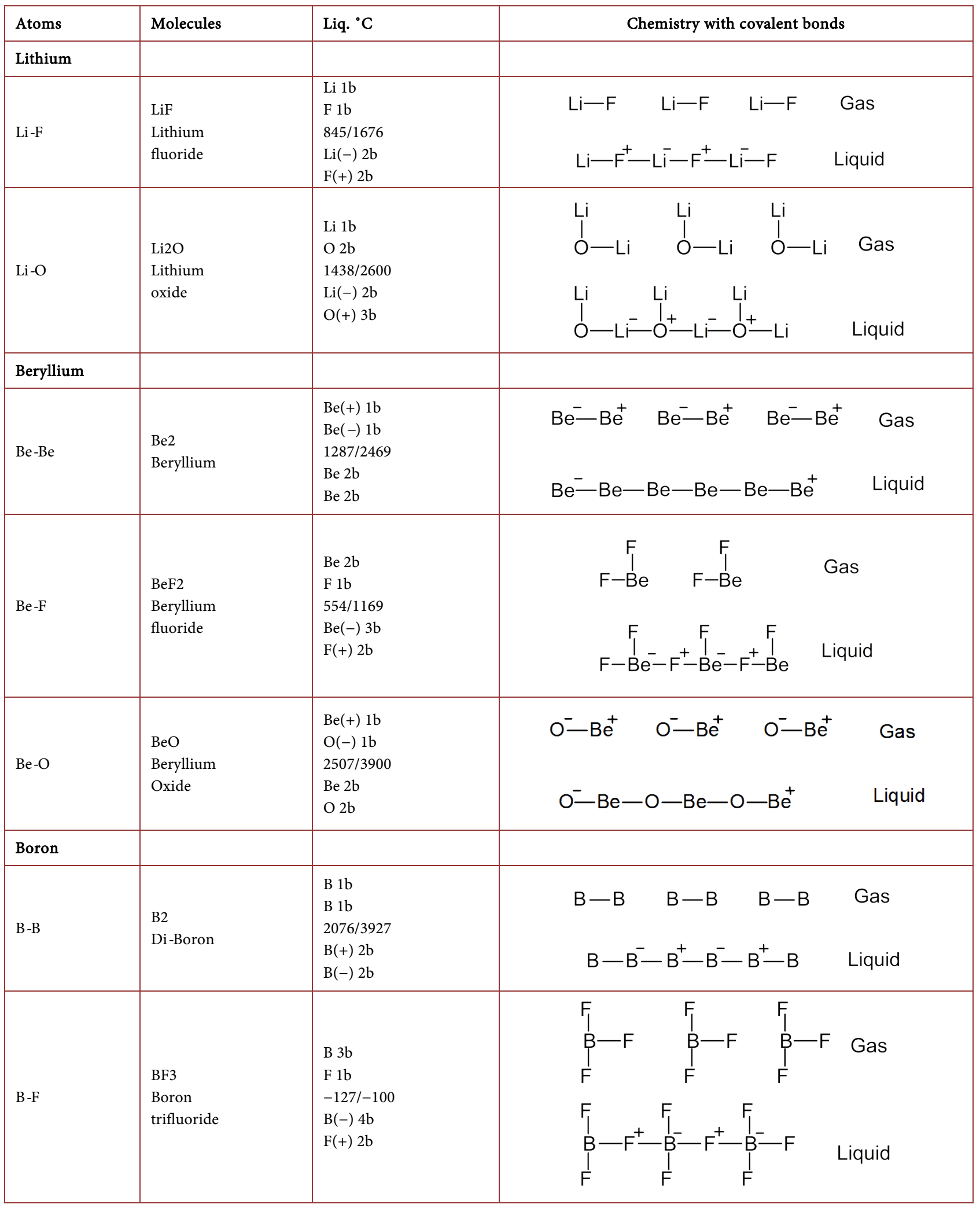




\section{Continued}

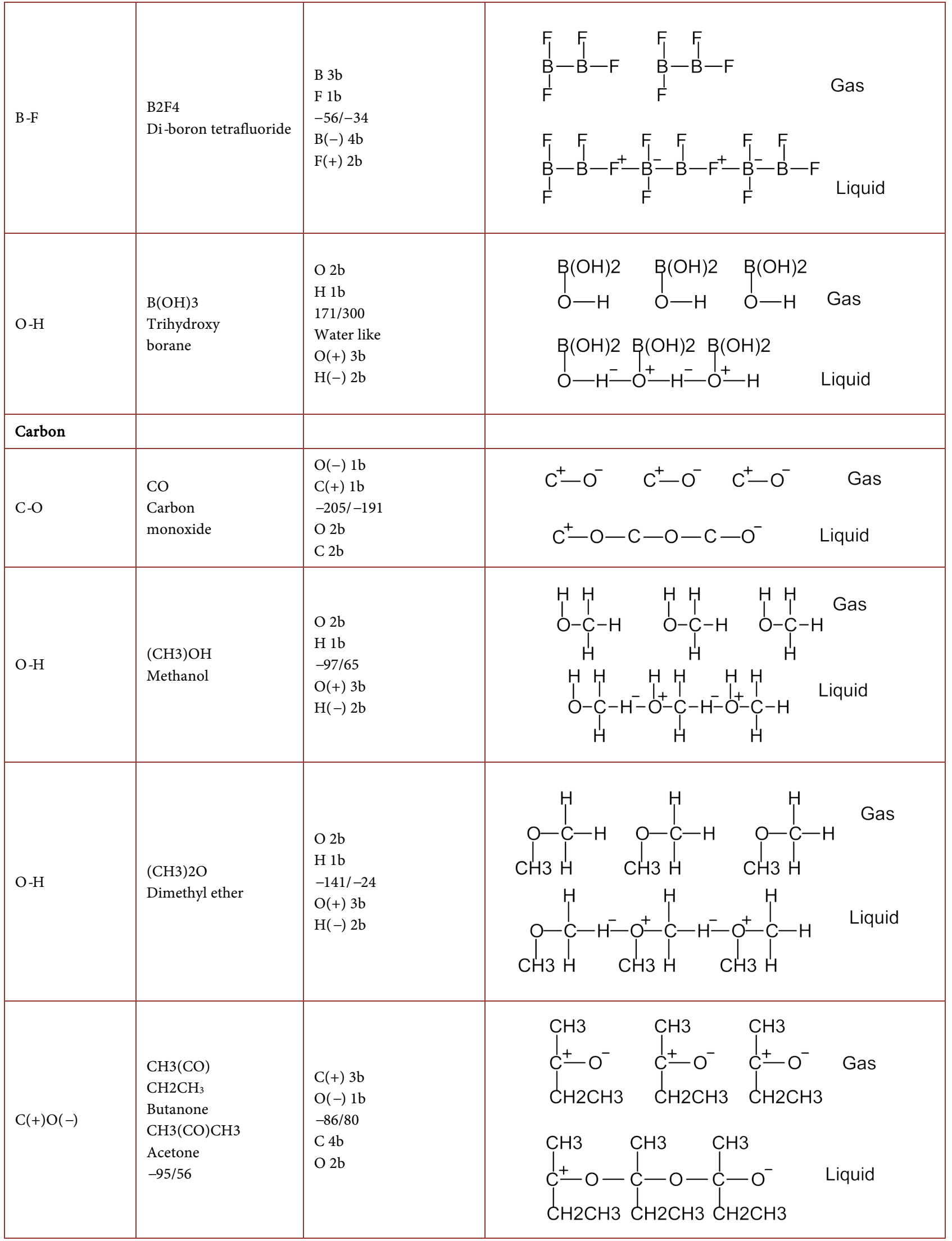




\section{Continued}

\begin{tabular}{|c|c|c|c|}
\hline $\mathrm{O}(-) \mathrm{H}$ & $\begin{array}{l}\mathrm{CH} 2 \mathrm{O} 2 \\
\text { Formic Acid }\end{array}$ & $\begin{array}{l}\mathrm{O} 2 \mathrm{~b} \\
\mathrm{H} 1 \mathrm{~b} \\
8 / 101 \\
\text { Water like } \\
\mathrm{O}(+) 3 \mathrm{~b} \\
\mathrm{H}(-) 2 \mathrm{~b}\end{array}$ & $\underbrace{\mathrm{C}_{+}^{-}}_{\mathrm{H}-\mathrm{O}-\mathrm{C}_{+}^{+} \mathrm{O}-\mathrm{H}_{-}^{-} \mathrm{O}-\mathrm{C}_{+}^{+}-\mathrm{O}^{-}}$Liquid \\
\hline $\mathrm{O}(-) \mathrm{H}$ & $\begin{array}{l}\mathrm{CH} 3 \mathrm{COOH} \\
\text { Acetic acid }\end{array}$ & $\begin{array}{l}\mathrm{C}(+) 3 \mathrm{~b} \\
\mathrm{O}(-) 1 \mathrm{~b} \\
16 / 118 \\
\mathrm{C} 4 \mathrm{~b} \\
\mathrm{O} 2 \mathrm{~b}\end{array}$ & 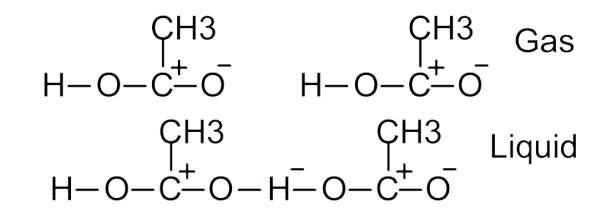 \\
\hline $\mathrm{O}(-) \mathrm{H}$ & $\begin{array}{l}\mathrm{CH} 2 \mathrm{CO} \\
\text { Ethenone }\end{array}$ & $\begin{array}{l}\mathrm{O}(-) 1 \mathrm{~b} \\
\mathrm{H} 1 \mathrm{~b} \\
-150 / 56 \\
\mathrm{O} 2 \mathrm{~b} \\
\mathrm{H}(-) 2 \mathrm{~b}\end{array}$ & 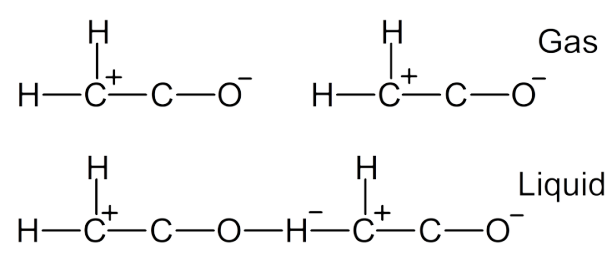 \\
\hline $\mathrm{O}(-) \mathrm{C}(+)$ & $\begin{array}{l}\mathrm{H} 2 \mathrm{CO} \\
\text { Formaldehyde }\end{array}$ & $\begin{array}{l}\mathrm{C}(+) 3 \mathrm{~b} \\
\mathrm{O}(-) 1 \mathrm{~b} \\
-92 /-19 \\
\mathrm{C} 4 \mathrm{~b} \\
\mathrm{O} 2 \mathrm{~b}\end{array}$ & I \\
\hline $\mathrm{O}(-) \mathrm{C}(+)$ & $\begin{array}{l}\mathrm{H}(\mathrm{CO}) \mathrm{NH} 2 \\
\text { Formamide } \\
\mathrm{CH} 3(\mathrm{CO}) \mathrm{NH} 2 \text { Acetami } \\
\text { de } \\
80 / 221\end{array}$ & $\begin{array}{l}\mathrm{C}(+) 3 \mathrm{~b} \\
\mathrm{O}(-) 1 \mathrm{~b} \\
2 / 220 \\
\mathrm{C} 4 \mathrm{~b} \\
\mathrm{O} 2 \mathrm{~b}\end{array}$ & ${ }_{\mathrm{NH} 2}^{\mathrm{C}_{+}^{+}}$ \\
\hline $\mathrm{O}(-) \mathrm{C}(+)$ & $\begin{array}{l}\mathrm{H}(\mathrm{CO}) \mathrm{N}(\mathrm{CH} 3) 2 \\
\text { Dimethyl } \\
\text { Formamide }\end{array}$ & $\begin{array}{l}\mathrm{C}(+) 3 \mathrm{~b} \\
\mathrm{O}(-) 1 \mathrm{~b} \\
-60 / 152 \\
\mathrm{C} 4 \mathrm{~b} \\
\mathrm{O} 2 \mathrm{~b}\end{array}$ & 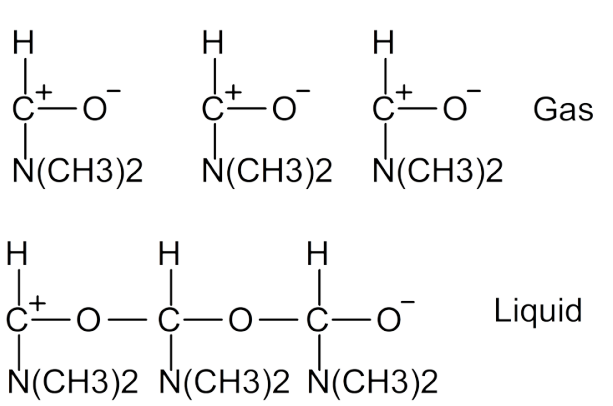 \\
\hline
\end{tabular}




\section{Continued}

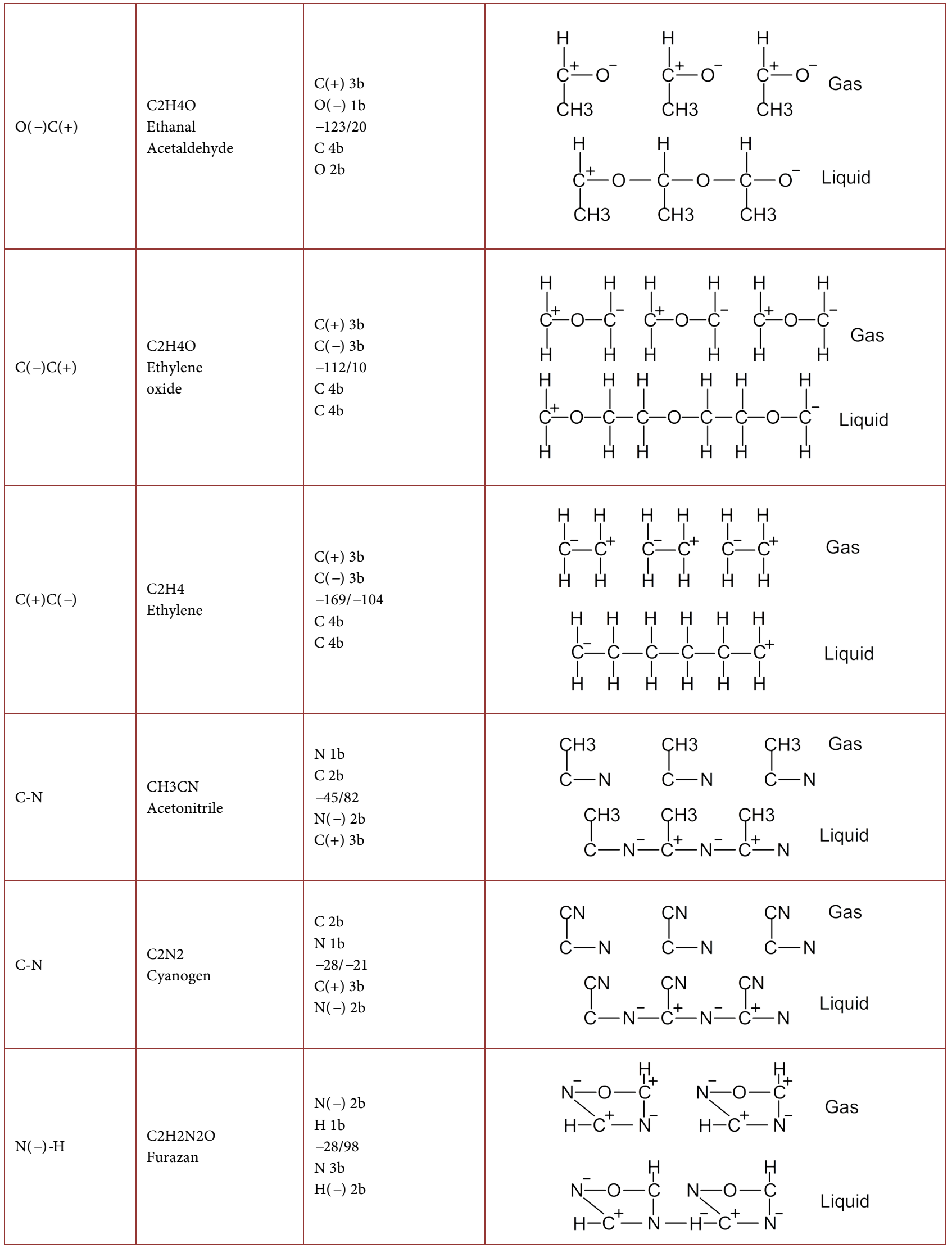


Continued

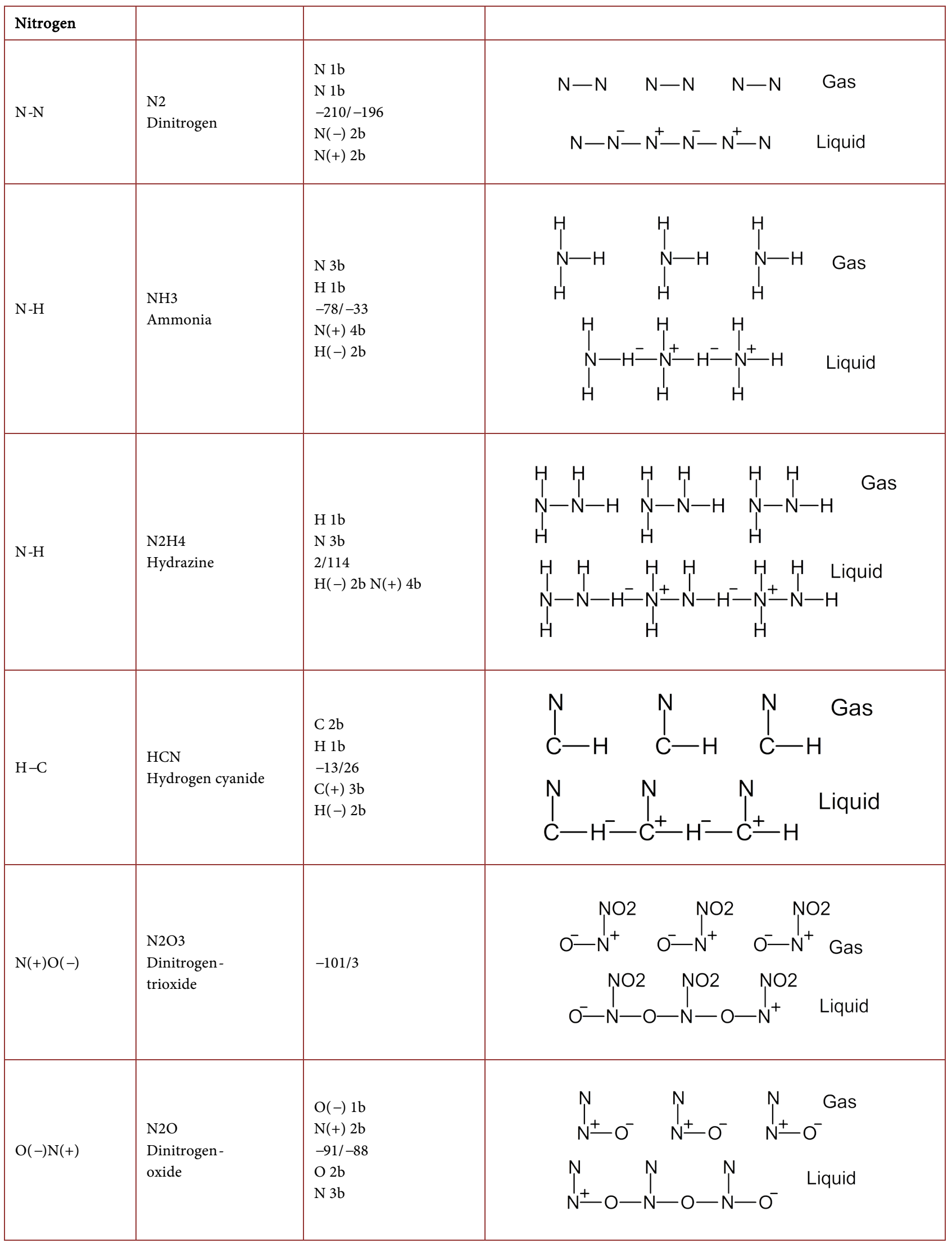




\section{Continued}

\begin{tabular}{|c|c|c|c|}
\hline $\mathrm{N}-\mathrm{H}$ & $\begin{array}{l}\mathrm{H} 3 \mathrm{NO} \\
\text { Hydroxyl- } \\
\text { amine }\end{array}$ & $\begin{array}{l}\mathrm{N} 3 \mathrm{~b} \\
\mathrm{H} 1 \mathrm{~b} \\
33 / 58 \\
\mathrm{~N}(+) 4 \mathrm{~b} \\
\mathrm{H}(-) 2 \mathrm{~b}\end{array}$ & Liquid \\
\hline $\mathrm{N}-\mathrm{H}$ & $\begin{array}{l}\text { (CH3)2NH } \\
\text { Dimethyl- } \\
\text { amine } \\
\text { amine }\end{array}$ & $\begin{array}{l}\text { N } 3 b \\
\mathrm{H} 1 \mathrm{~b} \\
-93 / 8 \\
\mathrm{~N}(+) 4 \mathrm{~b} \\
\mathrm{H}(-) 2 \mathrm{~b}\end{array}$ & 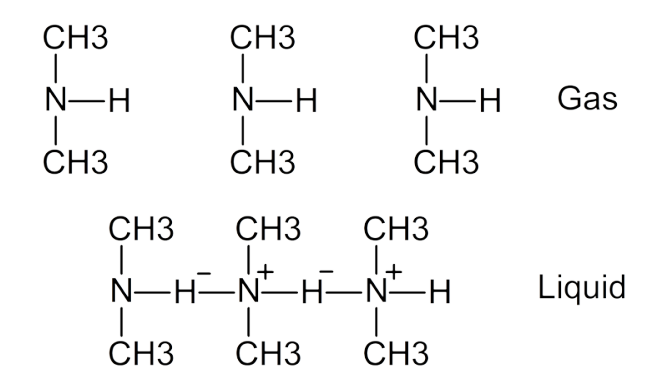 \\
\hline $\mathrm{N}-\mathrm{H}$ & $\begin{array}{l}\mathrm{CH} 3 \mathrm{NH} 2 \\
\text { Methylamine }\end{array}$ & $\begin{array}{l}\text { N } 3 b \\
\mathrm{H} 1 \mathrm{~b} \\
-93 /-7 \\
\mathrm{~N}(+) 4 \mathrm{~b} \\
\mathrm{H}(-) 2 \mathrm{~b}\end{array}$ & 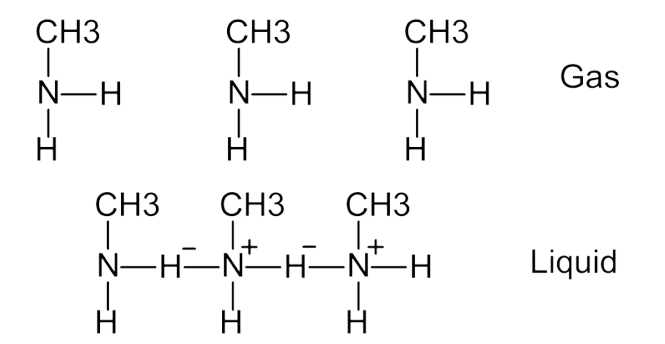 \\
\hline $\mathrm{O}(+) \mathrm{O}(-)$ & $\begin{array}{l}\mathrm{CH} 3 \mathrm{NO} 2 \\
\text { Nitromethane }\end{array}$ & $\begin{array}{l}\mathrm{O}(+) 1 b \\
\mathrm{O}(-) 1 b \\
-23 / 101 \\
\mathrm{O} 2 \mathrm{~b} \\
\mathrm{O} 2 \mathrm{~b}\end{array}$ & 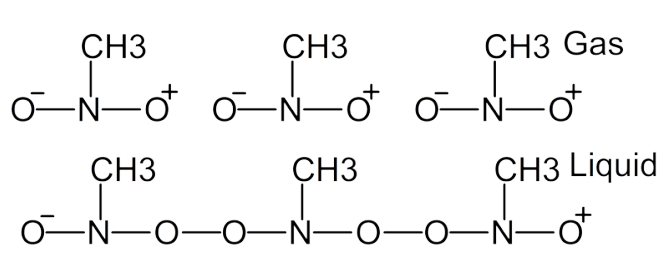 \\
\hline $\mathrm{N}-\mathrm{H}$ & $\begin{array}{l}\text { HN3 } \\
\text { Hydrazoic } \\
\text { Acid }\end{array}$ & $\begin{array}{l}\mathrm{N} 1 \mathrm{~b} \\
\mathrm{H} 1 \mathrm{~b} \\
-80 / 37 \\
\mathrm{~N}(+) 2 \mathrm{~b} \\
\mathrm{H}(=) 2 \mathrm{~b}\end{array}$ & 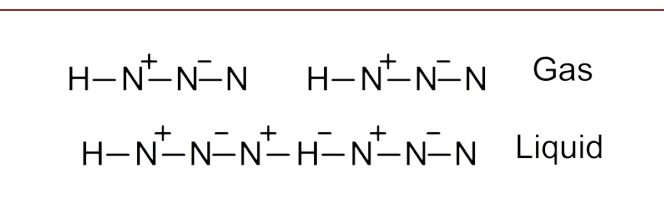 \\
\hline \multicolumn{4}{|l|}{ Oxygen } \\
\hline $\mathrm{O}-\mathrm{O}$ & $\begin{array}{l}\text { O2 } \\
\text { Dioxygen }\end{array}$ & $\begin{array}{l}\mathrm{O}(+) 1 \mathrm{~b} \\
\mathrm{O}(-) 1 \mathrm{~b} \\
-219 /-183 \\
\mathrm{O} 2 \mathrm{~b} \\
\mathrm{O} 2 \mathrm{~b}\end{array}$ & $\begin{array}{l}\mathrm{O}_{-}^{-} \mathrm{O}^{+} \mathrm{O}_{-}^{-} \mathrm{O}^{+} \quad \mathrm{O}_{-}^{-} \mathrm{O}^{+} \text {Gas } \\
\mathrm{O}_{-}^{-} \mathrm{O}-\mathrm{O}-\mathrm{O}-\mathrm{O}-\mathrm{O}^{+} \text {Liquid }\end{array}$ \\
\hline
\end{tabular}


Continued

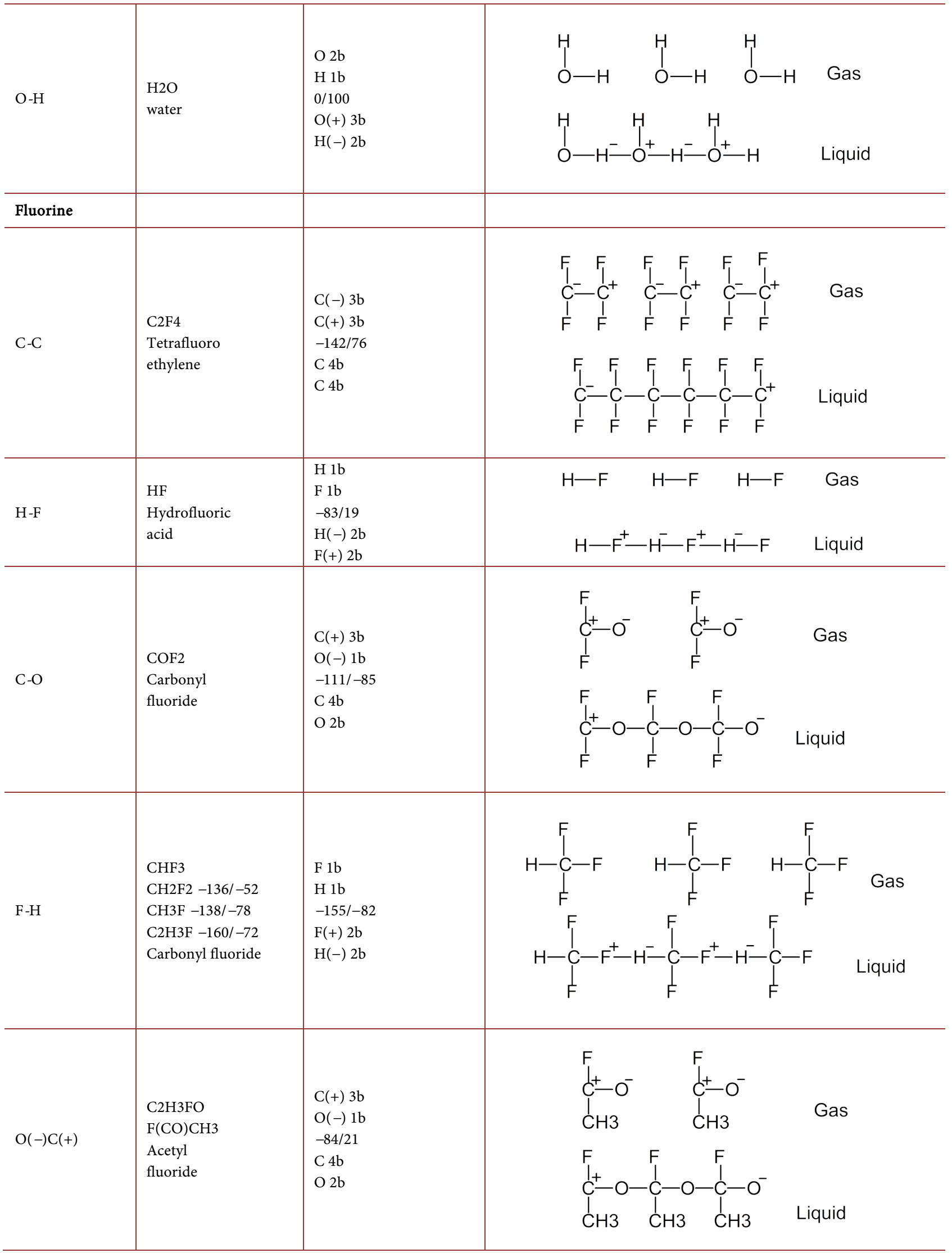


tries to propose such liquid structures which are deduced from the gaseous one using rules described in this article.

In Table 2, molecules names are listed in column 2 and the drawings of about 40 molecules are in column 4 in which gases are drawing above the structure of its liquid phase.

To lower the number of drawn molecules in this paper, only atoms coming from the two first rows of the classical periodic table are used.

Table 2 can be read as follow:

- The first column indicates the two atoms concerned by the formation of a new bond involved in the three other columns of the same row.

- The second column gives the name and the formula of the concerned molecules.

- The third column gives the number of bonds implied before and after the gas transformation into a liquid. It also gives the temperature range where molecules are in a liquid form $\left({ }^{\circ} \mathrm{C}\right)$.

- The fourth column shows drawings of the molecules in gas and liquid phases. They also indicate the positions of the atoms' charges in accordance with the rules described in this paper. Each drawing has atoms following the numbers of bonds given in the "specific periodic table for gaseous to liquids transformations" shown in Table 1.

\section{Discussion}

\subsection{Groups in the Periodic Table}

Atoms sharing the same cells in the Specific periodic table (Table 1) are isoelectronic atoms, i.e. they have the same electronic configuration. As seen in the table, different elements achieve isoelectronicity thanks to their charging status. For instance, $\mathrm{F}(+), \mathrm{O}($ neutral) and $\mathrm{N}(-)$ are isoelectronic atoms and positioned in the same cell of Table 1 .

Another particularity is the presence of two groups: organic atoms (green) and inorganic atoms. In each group, atoms show opposite behaviors when their number of electrons increased. As the total number of electrons increases, the inorganic group can gain new covalent bonds whereas the organic group loses its ability to make new bonds. Li, Be and B have 1, 2, 3 bonds respectively, whereas $\mathrm{N}, \mathrm{O}$ and $\mathrm{F}$ have 3, 2, 1 bonds respectively.

\subsection{Specifics in the Periodic Table}

- Carbon shows both behaviors, belonging partly to the inorganic and partly to the organic group. $\mathrm{C}(+)$ and $\mathrm{C}(-)$ cannot erect more than three bonds whereas $\mathrm{C}$ (neutral) has four bonds.

- Inorganic atoms can erect most bonds when negatively charged. However, negatively charged inorganic atoms can only connect by using one of their own electron pairs. It cannot accept an electron pair coming from another atom. For instance, BF4(-) cannot become BF5(2-). This is compatible with 
the limitation of single charged atoms in any compounds.

- Organic atoms, on the contrary, can build most bonds when positively charged. This allows a new covalent bond built with an external electron pair. Effectively this is possible, but the number of bonds is automatically decreased by the transfer of a pair in the inner shell. $\mathrm{O}(+)$ with 3 bonds can become $\mathrm{O}$ (neutral) with two bonds, only when its highest number of bonds is lowered to two. Here again, it might be interesting in the future to determine the physics behind it.

\subsection{Van der Waals in Chemistry}

Chemistry mainly studies atoms' interaction in molecules as being covalent bonds, which involve the sharing of electrons [7]. Covalent bonds involve very strong forces, as in diamond crystals [18], but very local forces, with a range not beyond two involved atoms. There are other non-covalent forces that result from electromagnetic interactions between molecules [19]. Van der Waals forces are classified in this second category. These forces do not result from chemical electronics [20]. They are very weak compared to covalent bonds forces. In the same way, van der Waals' equations are mostly used in molecular physics to give a relation between pressure, temperature and volume [21]. It also predicts transition between vapor and liquid in a macroscopic scale.

As this paper focuses on the formation of new covalent bonds, it seems very difficult to compare both covalent and non-covalent theories.

\subsection{Association and Dissociation of Molecules}

Our previous article [15] focused on molecular dissociation, the disappearance of an electron pair covalently connecting two atoms. The present paper is centered on the reverse process, association, as the creation of a new covalent bond between two atoms. In other words, the bond results from the displacement of an electron pair originating from one of the concerned atoms, to become a bonding pair. Both dissociation and association processes are truly based on one single idea: the movement of an electron pair that is composed of two inseparable electrons.

\section{Conclusion}

According to the rules proposed in this paper, gaseous molecules have neutral and/or with single charged atoms. These atoms are only single bonded with surrounded atoms and the number of bonds is indicated by a specific periodic table also proposed in this paper. To form a liquid, a new covalent bond appears. Charges' positions are modified still following the specific periodic table. This article details how electrons' pairs are moved to be compatible with these molecular modifications. By drawing several liquid formations with gaseous molecules, chemical processes are completely explained with electron pairs displacements. The next step might be to use such a process to illustrate ion formations in liquids. 


\section{Conflicts of Interest}

The author declares no conflicts of interest regarding the publication of this paper.

\section{References}

[1] Rumble, J. (2015) CRC Handbook of Chemistry and Physics. CRC Press, Boca Raton, FL, 2677 p.

[2] Auvert, G. (2015) How the Even-Odd Rule, by Defining Electrons Pairs and Charge Positions, Can Be Used as a Substitute to the Langmuir-Octet Rule in Understanding Interconnections between Atoms in Ions and Molecules. Open Journal of Physical Chemistry, 5, 28-38. https://doi.org/10.4236/ojpc.2015.52004

[3] https://en.wikipedia.org/wiki/Periodic table

[4] Auvert, G. (2014) Improvement of the Lewis-Abegg-Octet Rule Using an "Even-Odd" Rule in Chemical Structural Formulas: Application to Hypo and Hyper-Valences of Stable Uncharged Gaseous Single-Bonded Molecules with Main Group Elements. Open Journal of Physical Chemistry, 4, 60-66. https://doi.org/10.4236/ojpc.2014.42009

[5] Auvert, G. (2014) Chemical Structural Formulas of Single-Bonded Ions Using the “Even-Odd” Rule Encompassing Lewis's Octet Rule: Application to Position of Single-Charge and Electron-Pairs in Hypo- and Hyper-Valent Ions with Main Group Elements. Open Journal of Physical Chemistry, 4, 67-72. https://doi.org/10.4236/ojpc.2014.42010

[6] https://en.wikipedia.org/wiki/Liquid

[7] https://en.wikipedia.org/wiki/Covalent bond

[8] Auvert, G. (2014) The Even-Odd Rule on Single Covalent-Bonded Structural Formulas as a Modification of Classical Structural Formulas of Multiple-Bonded Ions and Molecules. Open Journal of Physical Chemistry, 4, 173-184.

https://doi.org/10.4236/ojpc.2014.44020

[9] Auvert, G. (2014) Coherence of the Even-Odd Rule with an Effective-Valence Isoelectronicity Rule for Chemical Structural Formulas: Application to Known and Unknown Single-Covalent-Bonded Compounds. Open Journal of Physical Chemistry, 4, 126-133. https://doi.org/10.4236/ojpc.2014.43015

[10] Auvert, G. (2017) Difference in Number of Electrons in Inner Shells of Charged or Uncharged Elements in Organic and Inorganic Chemistry: Compatibility with the Even-Odd Rule. Open Journal of Physical Chemistry, 7, 72-88.

https://doi.org/10.4236/ojpc.2017.72006

[11] https://en.wikipedia.org/wiki/Chemical compound

[12] Auvert, G. (2018) A Specific Periodic Table for Chemistry of Organic, Semi-Organic and Inorganic Elements: Compatibility with the Even-Odd Rule, the Number of Electrons and the Isoelectronicity Rule. Open Journal of Physical Chemistry, 8, 57-66. https://doi.org/10.4236/ojpc.2018.82004

[13] Auvert, G. and Auvert, M. (2015) Chemical Bonds between Charged Atoms in the Even-Odd Rule and a Limitation to Eight Covalent Bonds per Atom in Centered-Cubic and Single Face-Centered-Cubic Crystals. Open Journal of Physical Chemistry, 5, 93-105. https://doi.org/10.4236/ojpc.2015.54010

[14] Auvert, G. and Auvert, M. (2016) The Even-Odd and the Isoelectronicity Rules Applied to Single Covalent Bonds in Ionic, Double-Face-Centered Cubic and Diamond-Like Crystals. Open Journal of Physical Chemistry, 6, 21-33.

https://doi.org/10.4236/ojpc.2016.62002 
[15] Auvert, G. (2019) Basic Steps in Chemical Dissociation of Gaseous Molecules Using an Even-Odd Rule, a Specifically Adapted Periodic Table and a Covalent Bonding Rule. Open Journal of Physical Chemistry, 9, 88-105.

https://doi.org/10.4236/ojpc.2019.92006

[16] https://en.wikipedia.org/wiki/Oil

[17] Greenwood, N.N. and Earnshaw, A. (1998) Chemistry of the Elements. 2nd Edition, Butterworth-Heinemann, Oxford.

[18] https://en.wikipedia.org/wiki/Diamond

[19] https://en.wikipedia.org/wiki/Non-covalent interactions

[20] https://en.wikipedia.org/wiki/Van der Waals force

[21] https://en.wikipedia.org/wiki/Van der Waals equation 